\title{
Expanding the phenotype of CRYAA nucleotide variants to a complex presentation of anterior segment dysgenesis
}

\author{
Andrey V. Marakhonov ${ }^{1 *}$ (D, Anna A. Voskresenskaya ${ }^{2}$, Maria Jose Ballesta ${ }^{3,4}$, Fedor A. Konovalov, \\ Tatyana A. Vasilyeva', Fiona Blanco-Kelly ${ }^{4,6}$, Nadezhda A. Pozdeyeva², Vitaly V. Kadyshev', \\ Vanesa López-González ${ }^{3,4}$, Encarna Guillen ${ }^{3,4}$, Carmen Ayuso ${ }^{4,6}$, Rena A. Zinchenko ${ }^{1}$ and Marta Corton ${ }^{4,6 *}$
}

\begin{abstract}
Background: Mutations in CRYAA, which encodes the a-crystallin protein, are associated with a spectrum of congenital cataract-microcornea syndromes.

Results: In this study, we performed clinical examination and subsequent genetic analysis in two unrelated sporadic cases of different geographical origins presenting with a complex phenotype of ocular malformation. Both cases manifested bilateral microphthalmia and severe anterior segment dysgenesis, primarily characterized by congenital aphakia, microcornea, and iris hypoplasia/aniridia. NGS-based analysis revealed two novel single nucleotide variants occurring de novo and affecting the translation termination codon of the CRYAA gene, c.520T > $\mathrm{C}$ and c.521A > C. Both variants are predicted to elongate the C-terminal protein domain by one-third of the original length.
\end{abstract}

Conclusions: Our report not only expands the mutational spectrum of CRYAA but also identifies the genetic cause of the unusual ocular phenotype described in this report.

Keywords: CRYAA, Microphthalmia, Microcornea, Congenital aphakia, NGS, Anterior segment dysgenesis, Aniridia

\section{Background}

Embryonic lens development is a critical step during eye organogenesis, especially of the anterior segment [1]. Congenital aphakia is a rare developmental disorder characterized by the absence of the lens. Primary aphakia arises in the first 4 weeks of embryogenesis from a lack of lens induction caused by genetic defects, teratogenic effects or rubella virus infection [2-4]. Secondary

\footnotetext{
* Correspondence: marakhonov@generesearch.ru; mcorton@fjd.es

'Research Centre for Medical Genetics, Moskvorechie Str., 1, Moscow, Russian Federation

${ }^{4}$ Center for Biomedical Network Research on Rare Diseases (CIBERER), ISCIII Instituto de Salud Carlos III, Madrid, Spain

Full list of author information is available at the end of the article
}

congenital aphakia occurs as a result of spontaneous resorption or intrauterine rejection of the developing lens [5]. Congenital aphakia is usually reported in association with other severe ocular conditions, such as the sclerocornea-microphthalmia-aphakia complex caused by FOXE3 mutations [6].

Lens crystallins $\left(\alpha-, \beta-\right.$, and $\left.\gamma^{-}\right)$are the major components of lens fiber cells and are required for maintaining the clarity and refractive properties of the lens $[7,8]$. In addition to the function of crystallins as molecular chaperones regulating correct protein folding [9], several crystallins are expressed early during lens organogenesis and fiber cell differentiation, acting as apoptotic 
regulators [7]. Molecular defects in several crystallin genes lead to congenital cataracts. Missense mutations in the CRYAA gene, which encodes $\alpha \mathrm{A}$-crystallin, lead to autosomal dominant congenital cataract with or without microcornea (OMIM \#604219) [10, 11], as well as to rare and severe presentations of cataract, microphthalmia, and iris coloboma [12].

To date, 15 missense mutations, 3 small in-frame deletions, and one frame-shifting variant affecting CRYAA are registered in publicly available databases as being associated with autosomal dominant congenital cataract with or without microcornea (OMIM \#604219) [10, 11]. An additional nonsense variant p.(Trp9*) demonstrates an autosomal recessive mode of inheritance; thus, it has been described only in the homozygous state [13]. Missense variants are thought to produce a relatively mild phenotype of congenital cataract related to a dominant negative mechanism of CRYAA-associated cataractogenesis [14]. Most of these changes are at hotspots and alter highly conserved arginine residues located on the N-terminal and crystallin domains (Fig. 1a). Some of these mutations, such as p.(Arg12Cys), p.(Arg12Leu), p.(Arg21Trp) and p.(Arg116Cys), have also been associated with a more complex phenotype of congenital cataracts with microphthalmia and microcornea and in some cases in association with other developmental defects of the anterior segment, primarily with iris coloboma [12, 15-18]. Additionally, microcornea and congenital vascularized corneal opacity have also been associated with p.(Arg116His) [19]. Thus, $\alpha$ Acrystallin seems to play a role in anterior segment development that has not been identified to date.

In this study, we identified two novel read-through CRYAA variants as causes of a novel complex phenotype, primarily characterized by congenital aphakia, microphthalmia, iris hypoplasia and posterior anomalies. This gene was not previously associated with complex panocular maldevelopment; therefore, we expanded not only the mutational spectrum of CRYAA but also the associated phenotypes.

\section{Results}

In this study, we describe two unrelated sporadic cases from different geographical origins (Russia and Spain), presenting a notably rare form of microphthalmia and congenital aphakia. Both patients share a similar panocular phenotype of bilateral microphthalmia and severe anterior segment dysgenesis, primarily characterized by congenital aphakia, microcornea, and iris hypoplasia. The primary ophthalmological findings of both patients are summarized in Table 1.

Case 1 is a 27-year-old Caucasian female with bilateral microphthalmia, microcornea, partial aniridia, congenital aphakia, nystagmus, strabismus, secondary glaucoma, and fovea and optic disc hypoplasia. The patient was born as a result of dizygotic twin pregnancy in a family without ophthalmological pathology (Fig. 1b). Data for the presence of intrauterine infection were not available. She was born at full term following a normal pregnancy. Ophthalmic examination revealed a decrease in the corneal dimensions, an increase in corneal thickness and lack of limbal stem cell deficiency. Anterior segment optical coherence tomography (AS-OCT) confirmed the presence of limbal palisades of Vogt in the inferior half of the limbus (Fig. 2), a marked reduction in the anterior chamber size, rudimentary temporal iris remnants and absence of a formed lens. However, the lens capsule was visualized in both eyes, with a $1.5-\mathrm{mm}$ diameter opaque lens substance being retained in the central optical zone and a Y-shaped suture in the left eye (LE) (Fig. 2). Fundus examination showed pale and small optic nerve, lack of foveal depression, and the intersection of large retinal vessels of the macular area. To date, no eye surgery has been performed. No extraocular anomalies were observed. No reliable data on the presence of the lens in this patient in childhood are available, but current ophthalmic data (discovery of the capsular bag and the remnants of the fetal lens nucleus) suggested that aphakia might be secondary, since the initial steps of lens development had occurred, and both lenses were reabsorbed. Ophthalmological examination of her brother (dizygotic twin) revealed only slight pigmentary dispersion on the anterior lens capsule with preserved visual acuity (20/20) in both eyes (Fig. 2). Her parents and other healthy siblings did not show ophthalmic or systemic pathology after clinical examination.

Case 2 is a 10-year-old Caucasian boy with bilateral microphthalmia, persistent fetal vasculature (PFV), microcornea, iris hypoplasia, congenital primary aphakia, and secondary glaucoma. He is the fifth child of unrelated healthy parents with no family history of congenital abnormalities or ocular diseases. He was born at full term after an uneventful pregnancy with a birth weight of $3.82 \mathrm{~kg}$. Ophthalmological examination at birth showed bilateral congenital leukocoria, corneal edema, severe hypotalamia (grade 2), lack of formed lens, severe anterolental PFV, dense pupillary membrane, iris hypoplasia, and typical iridohyaloid vessels. Biomicroscopy and ultrasound exams showed microcornea with severe opacity and retinal detachment of the right eye (RE) and dyscoria pupil and corneal edema of the left eye (LE). Fundus examination of LE revealed a pale and excavated optic disk; the RE was not assessable. Bilateral membranectomy, pupiloplasty, and anterior vitrectomy were performed at the age of 1 month without intraocular lens implantation. After this intervention, the patient developed several complications, including intraocular hemorrhages and retinal detachments in RE that were 

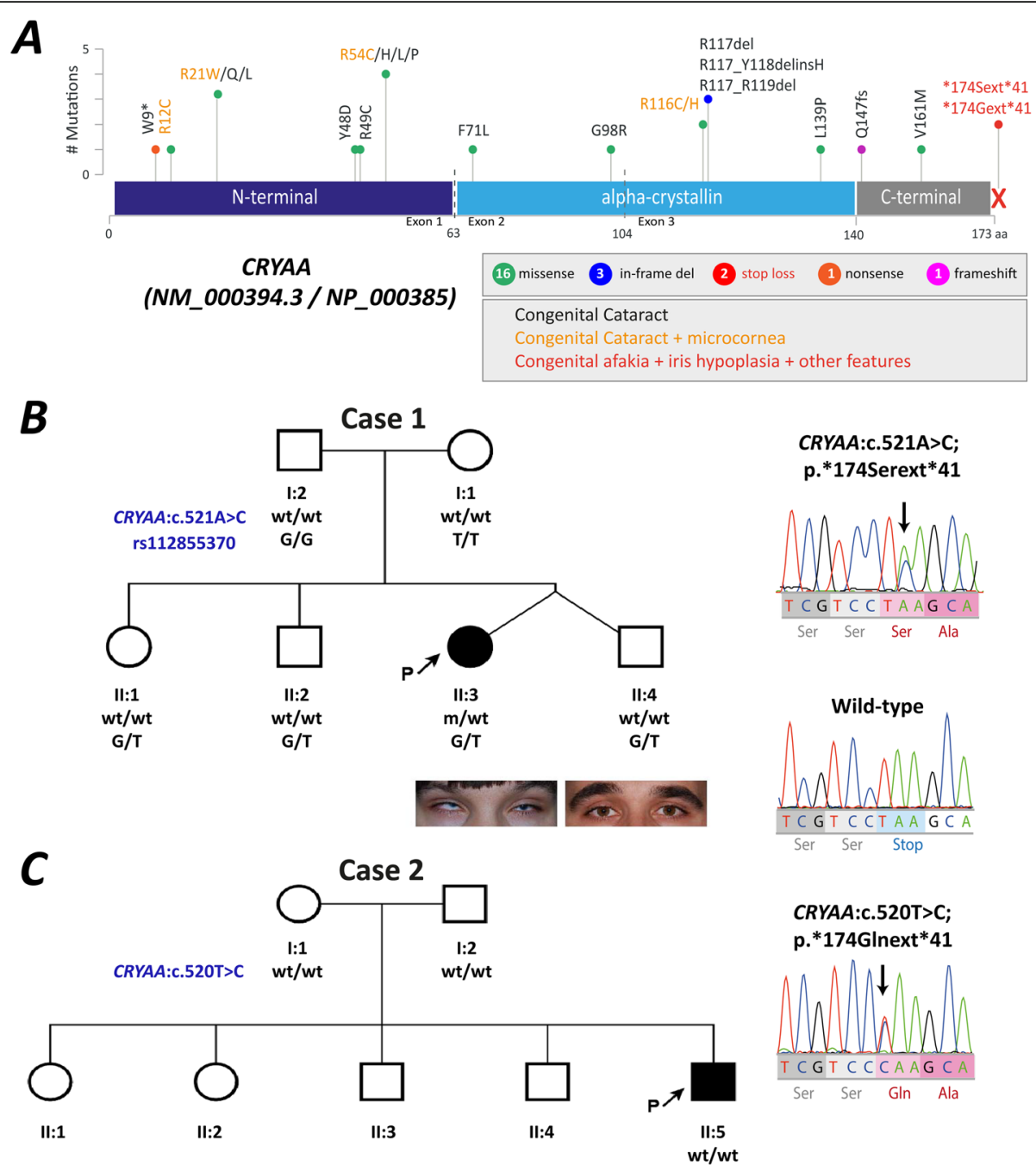

Fig. 1 a. Schematic representation of the CRYAA mutational spectrum. The upper and lower sections show the position of the exons and the protein structure with three CRYAA protein domains, respectively. The two novel stop-loss variants associated with a complex phenotype of congenital aphakia are represented in red. The pathogenic variants previously described in the literature for congenital cataracts or congenital cataract-microcornea syndrome are represented in black and orange, respectively. The number and the type of variants located in each amino acid residue are also indicated. Pedigrees and familial segregation of the two families (b and $\mathbf{c}$ ) carrying de novo run-on mutations in CRYAA. Arrows indicate the probands (P); wt/wt represents wild-type individuals; mut/wt indicates heterozygous individuals

derived to a pre-phthisis state. Consequently, an external orbital prosthesis was implanted to correct his facial asymmetry at 9 months of age. LE had several selfreleasing episodes of intravitreous hemorrhages and developed secondary glaucoma that was not controlled with hypotensive treatments. At 7 years of age, a second surgery was performed for implantation of an Ahmed glaucoma valve in the temporal superior sector of LE and for corneal scraping of band keratopathy. The last LE exam at 8 years of age showed horizontal pendular nystagmus and best-corrected visual acuity of 20/400 (corrected with +15 DS) that remained stationary for the last 4 years. He had normal psychomotor and cognitive development.
In both cases, next-generation sequencing (NGS) identified two likely pathogenic heterozygous substitutions in CRYAA affecting different nucleotides of the termination codon. In case 1 , whole exome sequencing (WES) found only 6 candidate variants in 6 genes after variant filtering (Suppl Table 1). However, according to the gene function and the associated phenotypes, only the CRYAA variant NM_000394.4:c.521A > C, which changes the translation termination codon to serine p.("174Serext"41), was the most likely cause (Fig. 1b). No other likely pathogenic variants in eye developmental genes were identified. In case 2, a custom capture-based NGS panel of 121 genes involved in eye developmental disorders identified the variant NM_000394.4:c.520T > C that 
Table 1 Ophthalmological features of the patients carrying CRYAA mutations

\begin{tabular}{|c|c|c|c|}
\hline Case & 1 & 2 & $\begin{array}{l}\text { Yamamoto, } 1988 \\
\text { (index case) }\end{array}$ \\
\hline Country of origin & Russia & Spain & Japan \\
\hline $\begin{array}{l}\text { Age (y) at last ophthalmic } \\
\text { revision }\end{array}$ & 27 & 8 (only LE) $^{a}$ & 49 \\
\hline Genetic change & c.521A > C; p. $\left(^{*} 174\right.$ Serext*41) & c.520T > C; p. $\left.{ }^{*} 174 G \ln e x t^{*} 41\right)$ & Unknown \\
\hline Segregation & de novo & de novo & Apparently dominant inheritance \\
\hline$B C V A(R E / L E)$ & LP / 20/400 & NA / 20/400 & LP / NLP \\
\hline Refraction & +8.5 & +15 & NA \\
\hline Microphthalmia & $+(\mathrm{B})$ & $+(\mathrm{B})$ & No \\
\hline $\begin{array}{l}\text { Anterior-posterior axis } \\
(\mathrm{mm})(\mathrm{RE} / \mathrm{LE})\end{array}$ & $18.67 / 19.06$ & NA / 13 & $23.4 / 23.7$ \\
\hline Lens & Congenital aphakia (B) & Congenital aphakia (B) & $\begin{array}{l}\text { Membranous structure (reabsorbed } \\
\text { cataract) }\end{array}$ \\
\hline Iris & Hypoplasia (B) & Hypoplasia (B) & Totally absent iris (LE), rudimentary iris (RE) \\
\hline Cornea & $\begin{array}{l}\text { Microcornea (B), increased } \\
\text { thickness (B) }\end{array}$ & $\begin{array}{l}\text { Microcornea, congenital corneal edema, } \\
\text { and cornea opacity (B) }\end{array}$ & Microcornea with corneal opacity (B) \\
\hline Cornea diameter $(\mathrm{mm})$ & $6.0 \times 6.5(B)$ & NA & $10.0 \times 10.5(B)$ \\
\hline $\begin{array}{l}\text { Central corneal thickness } \\
(\mu \mathrm{m})\end{array}$ & $790 / 820$ & NA & NA \\
\hline Posterior segment & $\begin{array}{l}\text { Optic nerve and foveal } \\
\text { hypoplasia (B) }\end{array}$ & $\begin{array}{l}\text { Intravitreous hemorrhages (B), retinal } \\
\text { detachments and atrophy (RE), and } \\
\text { glaucomatous cup (LE) }\end{array}$ & $\begin{array}{l}\text { Foveal hypoplasia, glaucomatous cup, and } \\
\text { dot hemorrhages (RE) }\end{array}$ \\
\hline Nystagmus & $+(\mathrm{B})$ & $+(\mathrm{B})$ & $+(\mathrm{B})$ \\
\hline Glaucoma & $+(\mathrm{B})$ & $+(\mathrm{LE})$ & $+(\mathrm{B})$ \\
\hline IOP (mm Hg) (RE/LE) & $33 / 33$ & $4 / 8^{a}$ & $70 / 70$ \\
\hline Other features & Strabismus & $\begin{array}{l}\text { Congenital leukocoria, anterior PFV and } \\
\text { hypotalamia (B) }\end{array}$ & Altered ERG \\
\hline Qx interventions & None & $\begin{array}{l}\text { Membranectomy, pupiloplasty and anterior } \\
\text { vitrectomy (B), orbital prosthesis (RE), and } \\
\text { Ahmed valve implant (LE) }\end{array}$ & $\begin{array}{l}\text { Laser membranectomy and trabeculectomy } \\
\text { (RE) }\end{array}$ \\
\hline
\end{tabular}

Notes: ${ }^{\mathrm{a}} \mathrm{RE}$ not assessable (prosthetic eye).

$B$ bilateral, $B C V A$ best corrected visual acuity, ERG electroretinogram, IOP intraocular pressure, $L E$ left eye, $L P$ light perception, NA not available, NLP no light perception, PFV persistent fetal vasculature, $Q x$ Surgical interventions, RE right eye, $y$ years

leads to a similar stop-loss change p.("174Glnext"41) (Fig. 1c). No additional likely pathogenic variants were identified.

Both variants are predicted to lead to a C-terminal extension (CTE) of 41 residues affecting the wellconserved polar domain of $\alpha \mathrm{A}$-crystallin (Fig. 1a). These variants were classified as likely pathogenic variants with the criteria PM2, PM4, PP3, PS2 using the American College of Medical Genetics (ACMG) recommendations (Table 2). First, both variants are novel, given their absence in population databases or in specific healthy controls from the same ethnic backgrounds. Additionally, familial segregation with confirmed paternity and maternity defined that both variants occurred as de novo events (Fig. 1b), also supporting their likely causality for disease presentation. Specifically, haplotype analysis of the variant c.521A >C and a closely linked SNP (rs112855370) enabled us to determine that this pathogenic variant occurred de novo in the paternal allele (Fig. 1b). Several in silico tools predicted that both variants are likely damaging. Splicing effects were discarded by using several in silico tools.

\section{Discussion}

To the best of our knowledge, no cases of a combination of congenital aphakia, iris hypoplasia, microphthalmia, and microcornea have been associated with CRYAA mutations. In addition to isolated congenital cataracts, defects in several lens crystallins may also lead to presentations of microphthalmia and cataracts, with or without microcornea, e.g., heterozygous missense CRYAA mutations [16, 17] and a homozygous CRYBB2 variant $[14,20]$. Other phenotypes of cataract, microcornea, and anterior segment dysgenesis have also been 


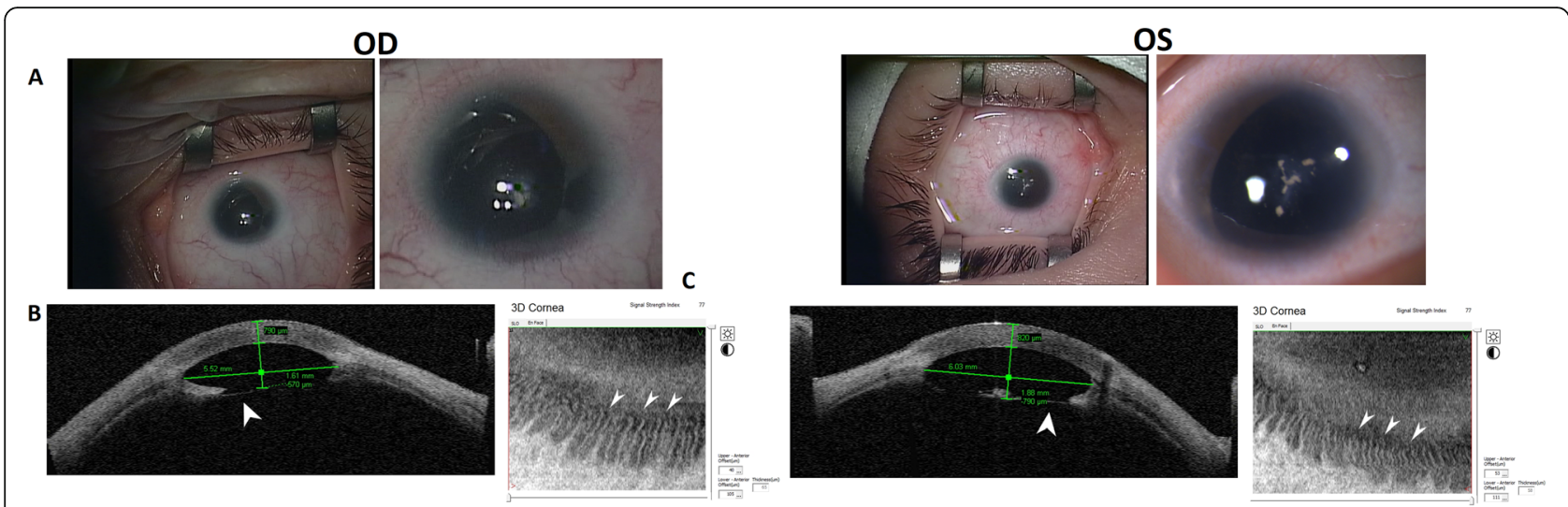

Fig. 2 Examination data for Case 1. a Images demonstrating a significant decrease in corneal dimensions, rudimentary remnants of the iris on the temporal side, and local opacity in the plane of the absent lens. b AS-OCT images (Visante OCT, Carl Zeiss, Germany) showing significant reduction in the size of the anterior chamber of the eye, increase in corneal thickness, lens capsule remnants, and absence of a formed lens (indicated by arrows). c AS-OCT images of the inferior limbus in EnFace mode (RTVue XR Avanti, Optovue, USA): hyperreflective parallel lines are seen that correspond to the limbal palisades of Vogt (indicated by arrows)

associated with PAX6 and MAF variants [21-24]. However, the most important distinguishing features of the phenotype described in this study are the remarkable lens absence, as well as the existence of panocular anomalies also affecting the posterior eye segment. In the Russian patient, the presence of lens remnants of nuclear matter, Y-shaped sutures, and some transparent peripheral parts of the lens capsule may indicate intrauterine lens underdevelopment along with the preservation of the fetal nucleus, rather than spontaneous lens resorption. Thus, aphakia seemed to be secondary but still congenital. Similar phenotypes of congenital aphakia, microphthalmia, and anterior segment dysgenesis have been only reported for some FOXE3 and PAX6 mutations, two transcription factors involved in lens vesicle formation [3, 25, 26]. Mutations in connexin GJA8 have also been recently associated with lens maldevelopment in patients with congenital aphakia or rudimentary lenses [24]. Three decades ago, Yamamoto et al. described a three-generation Japanese family in which at least 3 individuals manifested an ocular presentation resembling those described in this report [27]. In this family, the phenotypic description (OMIM 106230) was referred to as aniridia, microcornea, and spontaneously reabsorbed cataract. The common features of both the cases presented by us and the familial case by Yamamoto et al. are the panocular lesions of the eye, the absence of signs of somatic diseases and mental retardation in patients. The phenotypic heterogeneity of Japanese cases varies depending on the severity of corneal opacity, the degree of preservation of iris tissue and the angle structures of the anterior chamber of the eye and the lens (Table 2). At the same time, the Japanese authors do not report the presence of microphthalmia and persistent fetal vasculature in their patients.
Anamnestic data of several generations of the same family indicate cataract development at an early age, while slit-lamp examination visualizes a sufficiently large volume of preserved opaque cortical lens masses both in the optical center and at the periphery of the lens. The author describes such opacities as a membranous or spontaneously reabsorbed cataract. Although lens maldevelopment is also a shared characteristic, the timing of lens resorption in the Japanese family has not been determined. Therefore, it is not possible to conclude that it was congenital. No genetic data were reported for this family; thus, CRYAA mutations should be taken into consideration. In the cases we have described, OCT data and eye photographs enable us to visualize accurately the transparency of the peripheral parts of the lens without preserving the cortical masses, which makes it possible to understand early resorption of the lens material, possibly during its intrauterine development, making an aphakia to be secondary.

In this study, we identified for the first time two different CRYAA variants affecting the stop codon and likely leading to a similar CTE of 41 amino acid residues, which correspond to approximately one-third of the total protein length. Few variants have been identified in the C-terminus of CRYAA. We presume that in our cases, the severity of the damage to the eye structures might be associated with the mutation type affecting the CRYAA gene. This C-terminal domain seems to be important not only for protein solubility but also for the chaperone activity of $\alpha \mathrm{A}$-crystallin [9]. Functional studies and protein alignment analysis orthologous to crystallins suggest that an aberrant extension of the polar C-terminal domain of $\alpha$ A-crystallin would have a strong cytotoxic effect affecting all eye structures [28]. Consistent with this hypothesis, CTE mutations in other 


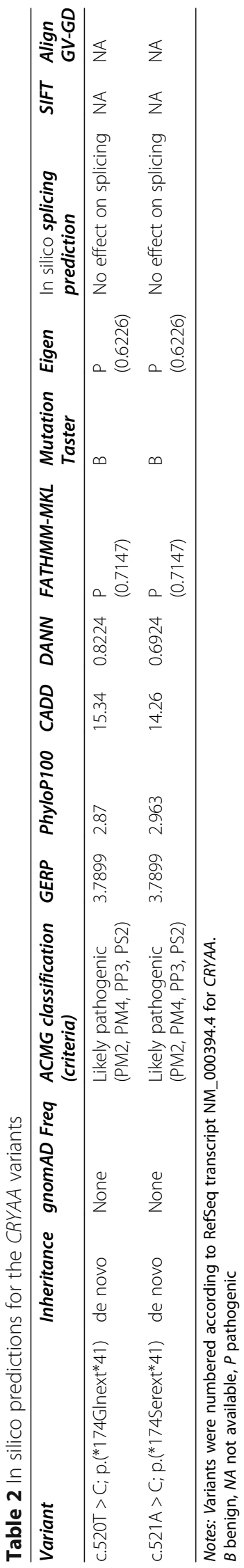


crystallins associated with congenital cataract usually cause more severe phenotypes than intragenic mutations. Thus, a 26 amino acid residues CTE caused by a read-trough mutation in CRYBB1 (NM_001887.3: c.757T > C, p. 253 Argext*26) resulted in congenital cataract-microcornea syndrome by increasing $\beta B 1$-crystallin hydrophobicity and promoting aggregate formation [28, 29]. The C-terminal domain plays an important role in the function of $\alpha \mathrm{A}$-crystallin as a survival protein, having a cytoprotective function in several ocular cells [30-32]. This domain was described as essential in preventing Bax-induced apoptosis [31, 32]. Remarkably, Bax- and Bak-deficient mice present PFV [33], which is likely related to apoptotic defects of hyaloid vessels. Strikingly, failure of fetal vasculature regression is one of the characteristic features of the patient carrying the variant c.520T $>$ C. Other possible pathogenic mechanisms underlying CTE mutations might be related to the apoptosis function of $\alpha \mathrm{A}$-crystallin during eye development. Further experiments are needed to test these hypotheses.

\section{Conclusions}

Since CRYAA is expressed early in the lens placode prior to exerting a structural role in developing fiber lenses [34], our work provides additional evidence for the involvement of $\alpha \mathrm{A}$-crystallin in lens formation. Furthermore, the results of our study may help to elucidate additional functions of crystallin in cell survival or autophagy regulation in lens epithelium and primary fiber cell differentiation, as well as fetal vasculature regression $[35,36]$. In addition, the intact lens orchestrates proper differentiation of different anterior segment structures through molecular signals from the lens epithelium [37]. Therefore, our findings also support the hypothesis that $C R Y A A$ could not influence lens embryogenesis but may also participate in the maldevelopment of different anterior segment structures, such as the cornea and iris.

\section{Patients and Methods}

\section{Patient cohort and samples}

Case 1 was recruited as part of a Russian study of anterior segment dysgeneses approved by the Institutional Review Board of the Research Centre for Medical Genetics (Moscow, Russia). The affected proband and her healthy relatives underwent detailed ophthalmic examination in the Cheboksary Branch of the S. Fyodorov Eye Microsurgery Federal State Institution (Cheboksary, Russia). AS-OCT (RTVue XR Avanti, Optovue, USA) using 3D Cornea (En Face mode) was performed as described previously [38].

Case 2 was recruited as part of a Spanish study of congenital ocular anomalies approved by the Ethics Committee of the Fundación Jiménez Díaz University
Hospital, Madrid, Spain. The affected proband and his healthy progenitors were clinically studied at the University Hospital Virgen de la Arrixaca, Murcia, Spain.

Written informed consent was obtained from all individuals involved in the study (or their legal guardians) prior to their participation. Genomic DNA was obtained using standard procedures from peripheral blood samples.

\section{Clinical genetic testing}

Following routine genetic testing, both patients had previously been screened for the most prevalent aniridiarelated gene, PAX6 (Case 1), or microphthalmia-related genes, such as OTX2 and SOX2 (Case 2), as described previously $[39,40]$. In both cases, no pathogenic variants were found.

\section{Whole-exome sequencing (case 1)}

WES was performed using an Illumina NextSeq 500 instrument with an average on-target coverage of $146 \times$ with Nextera Rapid Capture Exome v1.2 reagents (Illumina, San Diego, CA) for library preparation (Genomed Ltd., Moscow, Russia). Bioinformatic analysis was performed using an in-house software pipeline designed to detect both single-nucleotide variants (SNVs) and copy number variations (CNVs) as described [41]. Further filtering was performed by functional consequences and population frequencies (gnomAD $\mathrm{AF}<0.5 \%$ and $<0.1 \%$ for recessive and dominant genes, respectively), as well as clinical relevance according to the Human Phenotype Ontology database [42].

\section{Targeted resequencing (case 2)}

Targeted resequencing of 121 genes associated with eye developmental diseases was performed as previously reported [43]. Capture libraries for all coding and noncoding exons, including $20 \mathrm{bp}$ of intronic boundaries, were obtained using HaloPlex technology (Agilent Technologies, Santa Clara, CA). The libraries were pooled and sequenced on an Illumina NextSeq 500 instrument with 150-bp paired-end reads. Bioinformatic analysis was performed using standard procedures and custom in-house pipelines for both SNVs and CNVs, as previously described [43]. Variant prioritization was performed considering only novel variants or those with a minor frequent allele $<0.5 \%$ and $<0.1 \%$ for recessive and dominant genes, respectively, in the Genome Aggregation Database (gnomAD, http://gnomad.broadinstitute. org/) and the Spanish Variant Server (http://csvs.babelo mics.org/). Potentially functional SNVs and indels in coding regions were considered. In both cases, pathogenicity prediction analysis of the novel variants was carried out using Combined Annotation Dependent Depletion (CADD, http://cadd.gs.washington.edu/), GERP, 
PhyloP100, DANN, FATHMM-MKL, Mutation Taster and Eigen from Varsome [44], as well as splicing tools (Human Splicing Finder 3.1, Splicing Sequence Finder, MaxtEntScan, NNSPLICE) on Alamut software (Interactive Biosoftware, France) as well as newer tools based on neural networks (SpliceAI [45] and MMSplice [46]). The identified variants were classified for pathogenicity following the recommendations of the American College of Medical Genetics and Genomics (ACMG) [47].

\section{Sanger sequencing}

All pathogenic CRYAA variants retained after filtering from the WES or targeted resequencing data were confirmed by Sanger sequencing using specifically designed primers for exon 3 (available on request). Parental studies were also performed to determine whether these variants were inherited or appeared de novo. In Case 1, paternity and maternity were confirmed by multiplex analysis of 19 STR loci plus Amelogenin using the COrDIS Plus kit (Gordiz Ltd., Moscow, Russia) on the ABI PRISM $^{\circ}$ 3130XL Genetic Analyzer (Applied Biosystems Inc., Waltham, MA) according to the manufacturer's recommendations. In Case 2, paternity was confirmed using quantitative fluorescent PCR analysis of 26 genetic markers on chromosomes 13, 18, 21 and XY (Devyser Compact QF-PCR v3, Devyser AB, Hägersten, Sweden), as previously described [48].

\section{PCR-RFLP analysis (case 1)}

Polymerase chain reaction-restriction fragment length polymorphism (PCR-RFLP) analysis was used to determine the specific population frequency of the variant c.521A > C (Case 1) on a cohort of 110 healthy control individuals from the same ethnic background as Case 1 (Chuvash, a Turkic ethnic group, which is indigenous in the Chuvash Republic, Russian Federation). The genotyping of the wild-type allele (A) was performed by cutting with endonuclease EcoP15I (New England Biolabs, Inc., USA).

Linkage and parental origin of the affected allele for case 1 was performed by PCR-RFLP analysis followed by reamplification of the uncut mutant allele and Sanger sequencing with determination of the rs 112855370 genotype, which showed informativity in the family.

\section{Supplementary information}

Supplementary information accompanies this paper at https://doi.org/10. 1186/s13023-020-01484-8.

\section{Additional file 1}

\section{Acknowledgments}

We thank the families for their cooperation. We thank Dr. Richard H. Lozier for supporting our work and providing useful assistance.

\section{Authors' contributions}

AVM and MC designed the study, performed genetic testing, and participated in writing the manuscript; TAV performed molecular genetic analysis, interpreted the patient's data, and participated in the writing of the manuscript; FAK performed NGS data interpretation; AAV, WK, VG and MJB performed ophthalmological and medical genetic examination; RAZ, MC, $A V M, E G$, and CA designed the study and helped supervise the project. All authors read and approved the final draft of the manuscript.

\section{Funding}

The work reported in this article was partly supported by the Russian Foundation for Basic Research grant № 19-015-00122 and the state assignment of the Ministry of Science and Higher Education of the Russian Federation; the Spanish Institute of Health Carlos III (ISCIII)/European Regional Development Fund (ERDF) (PI17_01164); the Spanish Ministry of Economy and Competitiveness/FEDER (MINECO, SAF2013-46943-R); the University chair UAM-IIS-FJD of Genomic Medicine, the Regional Government of Madrid (CAM, B2017/BMD3721); and the Spanish Mutua Madrileña and Ramon Areces Foundations. M.C. is sponsored by the ISCIII Miguel Servet Program (CPII17_00006).

\section{Availability of data and materials}

The datasets used and/or analyzed during this study are available from the corresponding author upon reasonable request.

\section{Ethics approval and consent to participate}

The clinical and molecular genetic study was performed in accordance with the Declaration of Helsinki and was approved by the Institutional Review Board of the Federal State Budgetary Institution "Research Centre for Medical Genetics," Moscow, Russia, and Ethics Committee of the Fundación Jiménez Díaz University Hospital, Madrid, Spain, with written informed consent being obtained from each participant and/or their legal representative as appropriate.

\section{Consent for publication}

Consent for publication was obtained from the legal guardian of the patient.

\section{Competing interests}

The authors declare that they have no competing interests.

\section{Author details}

${ }^{1}$ Research Centre for Medical Genetics, Moskvorechie Str., 1, Moscow, Russian Federation. ${ }^{2}$ Cheboksary Branch of the S. Fyodorov Eye Microsurgery Federal State Institution, Cheboksary, Russian Federation. ${ }^{3}$ Medical Genetics Department, University Hospital Virgen de la Arrixaca, Murcia, Spain. ${ }^{4}$ Center for Biomedical Network Research on Rare Diseases (CIBERER), ISCIII - Instituto de Salud Carlos III, Madrid, Spain. ${ }^{5}$ Independent Clinical Bioinformatics Laboratory, Moscow, Russian Federation. ${ }^{6}$ Department of Genetics \& Genomics, Instituto de Investigación Sanitaria-Fundación Jiménez Díaz University Hospital, Universidad Autónoma de Madrid (IIS-FJD, UAM), Av. Reyes Católicos nº 2, 28040 Madrid, Spain.

Received: 20 February 2020 Accepted: 26 July 2020 Published online: 13 August 2020

\section{References}

1. Cvekl A, Zhang X. Signaling and gene regulatory networks in mammalian Lens development. Trends Genet. 2017;33(10):677-702.

2. Valleix S, Niel F, Nedelec B, Algros MP, Schwartz C, Delbosc B, Delpech M, Kantelip B. Homozygous nonsense mutation in the FOXE3 gene as a cause of congenital primary aphakia in humans. Am J Hum Genet. 2006;79(2):358-64.

3. Anjum I, Eiberg H, Baig SM, Tommerup N, Hansen L. A mutation in the FOXE3 gene causes congenital primary aphakia in an autosomal recessive consanguineous Pakistani family. Mol Vis. 2010;16:549-55.

4. Boger WP 3rd, Petersen RA, Robb RM. Spontaneous absorption of the lens in the congenital rubella syndrome. Arch Ophthalmol. 1981;99(3):433-4.

5. Johnson BL, Cheng KP. Congenital aphakia: a clinicopathologic report of three cases. J Pediatr Ophthalmol Strabismus. 1997;34(1):35-9.

6. Quiroz-Casian N, Chacon-Camacho OF, Barragan-Arevalo T, Nava-Valdez J, Lieberman E, Salgado-Medina A, Navas A, Graue-Hernandez EO, Zenteno JC. 
Sclerocornea-Microphthalmia-Aphakia complex: description of two additional cases associated with novel FOXE3 mutations and review of the literature. Cornea. 2018;37(9):1178-81.

7. Andley UP. Effects of alpha-crystallin on lens cell function and cataract pathology. Curr Mol Med. 2009;9(7):887-92.

8. Chen Y, Yi L, Yan GQ, Jang YX, Fang YW, Wu XH, Zhou XW, Wei LM Decreased chaperone activity of alpha-crystallins in naphthalene-induced cataract possibly results from C-terminal truncation. J Int Med Res. 2010; 38(3):1016-28

9. Horwitz J. Alpha-crystallin. Exp Eye Res. 2003;76(2):145-53.

10. Hansen L, Yao W, Eiberg H, Kjaer KW, Baggesen K, Hejtmancik JF, Rosenberg T. Genetic heterogeneity in microcornea-cataract: five novel mutations in CRYAA, CRYGD, and GJA8. Invest Ophthalmol Vis Sci. 2007; 48(9):3937-44.

11. Chen P, Dai Y, Wu X, Wang Y, Sun S, Xiao J, Zhang Q, Guan L, Zhao X, Hao $X$, et al. Mutations in the ABCA3 gene are associated with cataract-microcornea syndrome. Invest Ophthalmol Vis Sci. 2014;55(12): 8031-43.

12. Beby F, Commeaux C, Bozon M, Denis P, Edery P, Morlé L. New phenotype associated with an Arg116Cys mutation in the CRYAA gene: nuclear cataract, iris coloboma, and microphthalmia. Arch Ophthalmol. 2007; 125(2):213-6.

13. Pras E, Frydman M, Levy-Nissenbaum E, Bakhan T, Raz J, Assia El, Goldman $B$, Pras E. A nonsense mutation (W9X) in CRYAA causes autosomal recessive cataract in an inbred Jewish Persian family. Invest Ophthalmol Vis Sci. 2000; 41(11):3511-5

14. Litt M, Carrero-Valenzuela R, LaMorticella DM, Schultz DW, Mitchell TN, Kramer $\mathrm{P}$, Maumenee $\mathrm{H}$. Autosomal dominant cerulean cataract is associated with a chain termination mutation in the human beta-crystallin gene CRYBB2. Hum Mol Genet. 1997;6(5):665-8.

15. Vanita V, Singh JR, Hejtmancik JF, Nuernberg P, Hennies HC, Singh D, Sperling K. A novel fan-shaped cataract-microcornea syndrome caused by a mutation of CRYAA in an Indian family. Mol Vis. 2006;12:518-22.

16. Litt M, Kramer P, LaMorticella DM, Murphey W, Lovrien EW, Weleber RG. Autosomal dominant congenital cataract associated with a missense mutation in the human alpha crystallin gene CRYAA. Hum Mol Genet. 1998; 7(3):471-4.

17. Song Z, Si N, Xiao W. A novel mutation in the CRYAA gene associated with congenital cataract and microphthalmia in a Chinese family. BMC Med Genet. 2018;19(1):190.

18. Li J, Leng Y, Han S, Yan L, Lu C, Luo Y, Zhang X, Cao L. Clinical and genetic characteristics of Chinese patients with familial or sporadic pediatric cataract. Orphanet J Rare Dis. 2018;13(1):94.

19. Richter L, Flodman P, Barria von-Bischhoffshausen F, Burch D, Brown S Nguyen L, Turner J, Spence MA, Bateman JB. Clinical variability of autosomal dominant cataract, microcornea and corneal opacity and novel mutation in the alpha a crystallin gene (CRYAA). Am J Med Genet A. 2008;146A(7):833-42.

20. Bodker FS, Lavery MA, Mitchell TN, Lovrien EW, Maumenee $\mid H$. Microphthalmos in the presumed homozygous offspring of a first cousin marriage and linkage analysis of a locus in a family with autosomal dominant cerulean congenital cataracts. Am J Med Genet. 1990;37(1):54-9.

21. Hanson I, Churchill A, Love J, Axton R, Moore T, Clarke M, Meire F, van Heyningen $\mathrm{V}$. Missense mutations in the most ancient residues of the PAX6 paired domain underlie a spectrum of human congenital eye malformations. Hum Mol Genet. 1999;8(2):165-72.

22. Azuma N, Yamaguchi Y, Handa H, Hayakawa M, Kanai A, Yamada M. Missense mutation in the alternative splice region of the PAX6 gene in eye anomalies. Am J Hum Genet. 1999:65(3):656-63.

23. Jamieson RV, Munier F, Balmer A, Farrar N, Perveen R, Black GC. Pulverulent cataract with variably associated microcornea and iris coloboma in a MAF mutation family. Br J Ophthalmol. 2003;87(4):411-2

24. Ma AS, Grigg JR, Prokudin I, Flaherty M, Bennetts B, Jamieson RV. New mutations in GJA8 expand the phenotype to include total sclerocornea. Clin Genet. 2018;93(1):155-9.

25. Deml B, Reis LM, Lemyre E, Clark RD, Kariminejad A, Semina EV. Novel mutations in PAX6, OTX2 and NDP in anophthalmia, microphthalmia and coloboma. Eur J Hum Genet. 2016;24(4):535-41.

26. Plaisancie J, Ragge NK, Dollfus H, Kaplan J, Lehalle D, Francannet C, Morin G, Colineaux H, Calvas P, Chassaing N. FOXE3 mutations: genotype-phenotype correlations. Clin Genet. 2018;93(4):837-45.
27. Yamamoto Y, Hayasaka S, Setogawa T. Family with aniridia, microcornea, and spontaneously reabsorbed cataract. Arch Ophthalmol. 1988;106(4):502-4.

28. Leng XY, Li HY, Wang J, Qi LB, Xi YB, Yan YB. Congenital microcorneacataract syndrome-causing mutation X253R increases betaB1-crystallin hydrophobicity to promote aggregate formation. Biochem J. 2016;473(14): 2087-96.

29. Willoughby CE, Shafiq A, Ferrini W, Chan LL, Billingsley G, Priston M, Mok C, Chandna A, Kaye S, Heon E. CRYBB1 mutation associated with congenital cataract and microcornea. Mol Vis. 2005;11:587-93.

30. Hamann S, Metrailler S, Schorderet DF, Cottet S. Analysis of the cytoprotective role of alpha-crystallins in cell survival and implication of the alphaA-crystallin C-terminal extension domain in preventing Bax-induced apoptosis. PLoS One. 2013;8(2):e55372.

31. Kennedy D, Jager R, Mosser DD, Samali A. Regulation of apoptosis by heat shock proteins. IUBMB Life. 2014;66(5):327-38.

32. Hu WF, Gong L, Cao Z, Ma H, Ji W, Deng M, Liu M, Hu XH, Chen P, Yan Q, et al. alphaA- and alphaB-crystallins interact with caspase-3 and Bax to guard mouse lens development. Curr Mol Med. 2012;12(2):177-87.

33. Hahn $P$, Lindsten $T$, Tolentino $M$, Thompson CB, Bennett J, Dunaief JL. Persistent fetal ocular vasculature in mice deficient in bax and bak. Arch Ophthalmol. 2005;123(6):797-802.

34. Cvekl A, McGreal R, Liu W. Lens development and Crystallin gene expression. Prog Mol Biol Transl Sci. 2015;134:129-67.

35. Andley UP. The lens epithelium: focus on the expression and function of the alpha-crystallin chaperones. Int J Biochem Cell Biol. 2008;40(3):317-23.

36. Morozov V, Wawrousek EF. Caspase-dependent secondary lens fiber cell disintegration in alphaA-/alphaB-crystallin double-knockout mice. Development. 2006;133(5):813-21.

37. Zhang Y, Overbeek PA, Govindarajan V. Perinatal ablation of the mouse lens causes multiple anterior chamber defects. Mol Vis. 2007;13:2289-300.

38. Voskresenskaya A, Pozdeyeva N, Vasilyeva T, Batkov Y, Shipunov A, Gagloev $B$, Zinchenko R. Clinical and morphological manifestations of aniridiaassociated keratopathy on anterior segment optical coherence tomography and in vivo confocal microscopy. Ocul Surf. 2017;15(4):759-69.

39. Vasilyeva TA, Voskresenskaya AA, Käsmann-Kellner B, Khlebnikova OV, Pozdeyeva NA, Bayazutdinova GM, Kutsev SI, Ginter EK, Semina EV, Marakhonov AV, et al. Molecular analysis of patients with aniridia in Russian Federation broadens the spectrum of PAX6 mutations. Clin Genet. 2017; 92(6):639-44.

40. Blanco-Kelly F, Palomares M, Vallespin E, Villaverde C, Martin-Arenas R, VelezMonsalve C, Lorda-Sanchez I, Nevado J, Trujillo-Tiebas MJ, Lapunzina P, et al. Improving molecular diagnosis of aniridia and WAGR syndrome using customized targeted array-based CGH. PLoS One. 2017;12(2):e0172363.

41. Lozier ER, Konovalov FA, Kanivets IV, Pyankov DV, Koshkin PA, Baleva LS, Sipyagina AE, Yakusheva EN, Kuchina AE, Korostelev SA. De novo nonsense mutation in WHSC1 (NSD2) in patient with intellectual disability and dysmorphic features. J Hum Genet. 2018.

42. Köhler S, Carmody L, Vasilevsky N, Jacobsen JOB, Danis D, Gourdine JP, Gargano M, Harris NL, Matentzoglu N, McMurry JA, et al. Expansion of the human phenotype ontology (HPO) knowledge base and resources. Nucleic Acids Res. 2019:47(D1):D1018-27.

43. Ceroni F, Aguilera-Garcia D, Chassaing N, Bax DA, Blanco-Kelly F, Ramos P, Tarilonte M, Villaverde C, da Silva LRJ, Ballesta-Martinez MJ, et al. New GJA8 variants and phenotypes highlight its critical role in a broad spectrum of eye anomalies. Hum Genet. 2018.

44. Kopanos C, Tsiolkas V, Kouris A, Chapple CE, Albarca Aguilera M, Meyer R, Massouras A. VarSome: the human genomic variant search engine. Bioinformatics. 2019;35(11):1978-80.

45. Jaganathan K, Kyriazopoulou Panagiotopoulou S, McRae JF, Darbandi SF, Knowles D, Li YI, Kosmicki JA, Arbelaez J, Cui W, Schwartz GB, et al. Predicting splicing from primary sequence with deep learning. Cell. 2019; 176(3):535-48 e524.

46. Cheng J, Nguyen TYD, Cygan KJ, Celik MH, Fairbrother WG, Avsec Z, Gagneur J. MMSplice: modular modeling improves the predictions of genetic variant effects on splicing. Genome Biol. 2019;20(1):48.

47. Richards S, Aziz N, Bale S, Bick D, Das S, Gastier-Foster J, Grody WW, Hegde M, Lyon E, Spector E, et al. Standards and guidelines for the interpretation of sequence variants: a joint consensus recommendation of the American College of Medical Genetics and Genomics and the Association for Molecular Pathology. Genet Med. 2015;17(5):405-24. 
48. Martin-Merida I, Avila-Fernandez A, Del Pozo-Valero M, Blanco-Kelly F, Zurita O, Perez-Carro R, Aguilera-Garcia D, Riveiro-Alvarez R, Arteche A, Truillo-

Tiebas MJ, et al. Genomic landscape of sporadic retinitis Pigmentosa: findings from 877 Spanish cases. Ophthalmology. 2019;126(8):1181-8.

\section{Publisher's Note}

Springer Nature remains neutral with regard to jurisdictional claims in published maps and institutional affiliations.

Ready to submit your research? Choose BMC and benefit from:

- fast, convenient online submission

- thorough peer review by experienced researchers in your field

- rapid publication on acceptance

- support for research data, including large and complex data types

- gold Open Access which fosters wider collaboration and increased citations

- maximum visibility for your research: over $100 \mathrm{M}$ website views per year

At $\mathrm{BMC}$, research is always in progress.

Learn more biomedcentral.com/submissions 